\title{
A variação linguística nos livros didáticos do ensino fundamental
}

\section{The linguistic variation in didactic textbooks of elementary education II}

Carlos Wilson de Jesus Pedreira' https://orcid.org/0000-0002-4684-4925

Juliene Lopes Pedrosa ${ }^{2}$ https://orcid.org/0000-0003-4308-8762

\begin{abstract}
Resumo: Neste artigo, analisa-se o tratamento da variação linguística em dois livros didáticos de Língua Portuguesa do Ensino Fundamental II. Para realização desta pesquisa, foram selecionadas como material de investigação as obras Jornadas.port de Dileta Delmanto e Laiz B. de Carvalho e Singular \& plural: leitura, produção e estudos de linguagem de Laura de Figueiredo, Marisa Balthasar e Shirley Goulart - ambas indicadas pelo Programa Nacional do Livro Didático, PNLD, em 2012 - com o objetivo de verificar e avaliar como os livros didáticos supracitados tratam o fenômeno da variação linguística. A pesquisa parte de um trabalho bibliográfico/documental, ou seja, coleta de dados nos livros didáticos sobre a inserção da variação no ensino, observando o tratamento dado à variação, com base nos textos de alguns estudiosos como Bagno (2002, 2003, 2007), Bortoni-Ricardo (2004, 2005, 2008), Faraco (2008) e os PCNs (BRASIL, 1997, 1998). Como os livros didáticos foram aprovados pelo processo de avaliação do PNLD, isso significa que são considerados satisfatórios ao que se propõem. A análise conclui que os livros didáticos analisados apresentam deficiência na apresentação e tratamento da variação linguística, dando pouca contribuição para que o aluno assuma uma posição teórica, crítica e investigativa a respeito de regras variáveis.
\end{abstract}

Palavras-chave: Sociolinguística; Variação Linguística; Livro Didático.

\footnotetext{
${ }^{1}$ Universidade Federal da Paraíba; e-mail: carloswilsonpedreira@yahoo.com.br

${ }^{2}$ Universidade Federal da Paraíba; e-mail: julienepedrosa@yahoo.com
} 


\begin{abstract}
In this chapter, the treatment of linguistic variation is analyzed in two Portuguese-language textbooks of Elementary School II. To carry out this research, the works Jornadas.port by Dileta Delmanto and Laiz B. de Carvalho and Singular \& plural: reading, production and language studies by Laura de Figueiredo, Marisa Balthasar and Shirley Goulart - both indicated by the National Textbook Program, PNLD, in 2012 - with the aim of verifying and evaluating how the above mentioned textbooks treat the phenomenon of linguistic variation. The research starts from a bibliographical/documentary work, that is, data collection in the textbooks on the insertion of variation in teaching, observing the treatment given to variation, based on the texts of some scholars like Bagno (2002, 2003, 2007 ), Bortoni-Ricardo (2004, 2005, 2008), Faraco (2008) and the PCN (BRASIL, 1997, 1998). As the textbooks were approved by the PNLD evaluation process, this means that they are considered satisfactory to what they are proposed. The analysis concludes that the textbooks analyzed present a deficiency in the presentation and treatment of linguistic variation, giving little contribution so that the student assumes a theoretical, critical and investigative position regarding variable rules.
\end{abstract}

Keywords: Sociolinguistics; Linguistic Variation; Textbook

\title{
Introdução
}

Um dos maiores desafios enfrentados pelo professor de português, especialmente no Ensino Fundamental, diz respeito ao tratamento da variação linguística. Do ponto de vista estritamente linguístico, o erro não existe, o que existe são formas diferentes de usar os recursos potencialmente presentes na própria língua. É preciso enfatizar as tendências imanentes da língua para levar as pessoas em geral, os professores em particular, a assumir a convicção de que "os chamados 'erros' que nossos alunos cometem, têm explicação no próprio sistema evolutivo da língua. Portanto, podem ser previstos e trabalhados com uma abordagem sistêmica". (BORTONI-RICARDO, 2004, p. 9).

É comum nas escolas confundir-se o ensino de português com o ensino de gramática normativa ou ensino de nomenclaturas gramaticais, que nada se aproximam dos diferentes usos efetivos da língua nas diversas situações de interação. Um ensino que só faz o aluno se sentir mais confuso com tantas regras de uma língua que para ele é bastante distante do uso que ele faz da língua no seu convívio social. O que podemos constatar é que ainda prevalece nas aulas de Língua Portuguesa o ensino da gramática normativa, com base em prescrições de regras de uma variedade padrão ideal, descontextualizada do uso social, desvinculada de seu funcionamento.

Estudos sobre o tratamento da variação linguística no livro didático são desenvolvidos na tentativa de contribuir para favorecer ao aprendiz a produção e leitura de textos nos mais variados contextos de sua vida pública e privada, utilizando-se de variedades diferentes da língua. Os Parâmetros Curriculares Nacionais (1998), diferentemente do que ocorre na prática escolar, preveem que 
[...] o estudo da variação cumpre um papel fundamental na formação da consciência linguística e no desenvolvimento da competência discursiva do aluno, devendo estar sistematicamente presente nas atividades de Língua Portuguesa. (BRASIL, 1998, p.82)

Considerar, portanto, a variação como aspecto fundamental no desenvolvimento da competência discursiva do aluno é reconhecer o fato de que sua fala e escrita são construídas discursivamente por formas linguísticas que competem entre si. À medida que o aluno alcança um grau de letramento mais avançado, aumenta seu conhecimento linguístico, levando-o a optar por uma ou outra variante, a depender da sua necessidade discursiva, fazendo, assim, com que tenha consciência de que ele também realiza variação linguística. Como nos alerta Bechara (1991, p.14), “caberá ao professor e à escola como um todo transformar o aluno num poliglota dentro da sua própria língua histórica".

Infelizmente, essas orientações ainda não se aplicam às escolas que trabalham unicamente com uma variedade de língua homogênea, que se tem chamado de língua padrão ou norma-padrão na tentativa de padronizar a língua para que todos falem e escrevam numa língua sem variedades, negando a variação e a diversidade inerentes a toda e qualquer língua, como se isso fosse possível.

Sendo assim, há uma necessidade de um ensino de língua portuguesa pautado na reflexão sobre a realidade sociolinguística brasileira, em que convivem diferentes normas e variedades regionais, sociais, estilísticas. Dessa forma, o aluno conhecerá, analisará e estudará as variedades, não perpetuando o preconceito linguístico.

Assim, é de total responsabilidade das Instituições de Ensino promover um contato maior do aluno com as diversas variedades linguísticas existentes para que ele possa fazer suas escolhas no momento de interação, de forma adequada, uma vez que é o contexto de interação que determina a variedade linguística a ser usada. O aluno deve se sentir parte integrante da escola e ver que sua língua faz parte desse contexto, para que ele não pense que sua fala é "errada", "tosca", "feia", é a sua identidade como membro de uma comunidade linguística através da qual ele interage o tempo todo. Assim, ele vai entender que a escola não precisa consertá-la, mas, sim, ampliar seu leque de conhecimento em relação à sua língua.

Sobre o ensino da língua, a abordagem laboviana enfatiza que a questão não está na incapacidade do aluno em aprender o dialeto padrão, mas no comportamento do professor em relação ao dialeto desprestigiado do aprendiz. Se algo está interferindo no processo de aprendizagem, a ineficácia está na estrutura da escola que deve ser alterada. Essa compreensão nos faz refletir sobre o papel das instituições formadoras e, consequentemente, sobre a formação 
de professores para atuação na educação básica, de tal modo que estes não sejam reprodutores das desigualdades e não contribuam para perpetuar o fosso existente entre a classe mais prestigiada e a menos favorecida.

Nessa perspectiva, delineamos este texto, fruto da preocupação em discutir como está posto o ensino da língua materna no livro didático (LD) de Língua Portuguesa em relação às contribuições sociolinguísticas. Objetivamos analisar o tratamento da variação linguística em dois LDs de Língua Portuguesa do Ensino Fundamental II e conduzir o leitor a uma reflexão sobre o direcionamento dado à variação linguística nessas obras.

Foram selecionadas as obras Jornadas.port $7^{\circ}$ ano, de Dileta Delmanto e Laiz B. de Carvalho, e Singular \& Plural: Leitura, produção e estudos de linguagem $6^{\circ}$ ano, de Laura de Figueiredo, Marisa Balthasar e Shirley Goulart, ambos indicados pelo Programa Nacional do Livro Didático - PNLD. Desenvolvemos um estudo descritivo, com abordagem qualitativa, a partir da análise do tratamento da variação linguística.

\section{Contribuições da sociolinguística ao ensino de língua portuguesa}

Um dos maiores desafios das aulas de Português diz respeito, sem dúvida, ao tratamento da variação linguística e, fundamentalmente, aos saberes gramaticais - permeados de diferentes normas linguísticas - que devem estar presentes na escola. Com o amplo acesso dos brasileiros aos bancos escolares, especialmente no primeiro nível do ensino fundamental, a multifacetada realidade brasileira, em todas as suas expressões socioculturais, reflete-se na produtiva e saudável convivência de diversas variedades linguísticas na vida escolar.

As orientações oficiais propõem como alguns objetivos da área de Língua Portuguesa "conhecer e respeitar as diferentes variedades linguísticas do português falado" e "utilizar diferentes registros, inclusive os mais formais da variedade linguística valorizada socialmente, sabendo adequá-los às circunstâncias da situação comunicativa de que participam" (BRASIL, 1997, p.33), de outro, formulam como "objetos privilegiados de ensino-aprendizagem", "a língua escrita e o que se tem chamado de língua padrão" (BRASIL, 1998, p.33).

Segundo Martins et al. (2014, p.10), do conhecimento provido pelos pressupostos da Sociolinguística Variacionista, e com especial atenção pelos estudos desenvolvidos no Brasil, pelo menos três grandes contribuições merecem destaque:

(i) definição apurada de conceitos básicos para o tratamento adequado dos fenômenos variáveis;

(ii) reconhecimento da pluralidade de normas brasileiras, complexo tecido de variedades em convivência; e 
(iii) estabelecimento de diversas semelhanças entre o que se convencionou chamar "norma culta" e "norma popular", não obstante os estereótipos linguísticos (cf. LABOV, 2008[1972]) facilmente identificados pela maioria dos falantes.

A variação linguística tem sido objeto da apreciação de especialistas e não especialistas, de orientações bastante diversas, que, sob olhares igualmente diversificados, acabam por conceituar e/ou nomear de modo distinto elementos fundamentais à compreensão do fenômeno. Resulta dessa prática uma variedade de concepções acerca das chamadas normas linguísticas.

Esses limites imprecisos entre "norma", "modalidade" e "registro" não são propriedade exclusiva do discurso dos professores; na própria área científica e nas orientações oficiais do Ministério da Educação e Cultura (MEC) para a área de Língua Portuguesa, também se verifica a necessidade de delimitação conceitual.

Castilho (2002, p. 30) denomina um conceito amplo e um conceito estrito de norma. Esse conceito mais estrito é que seria de maior interesse para o ensino por entender-se como os usos e as atitudes de uma classe social de prestígio, distinguindo-se como norma objetiva, norma subjetiva e norma prescritiva, esta última encarada e difundida pela escola como sendo a representação única e exata da língua.

A primeira, denominada pelo autor como norma objetiva, explícita ou padrão real, é a linguagem efetivamente praticada pela classe social de prestígio, que se pode identificar no Brasil de hoje com a chamada classe culta, escolarizada. Costuma-se atribuir, muitas vezes, um perfil normativo, com intenção de regular o comportamento social, seja por parte da tradição gramatical (aquela que objetiva estabelecer um modelo clássico, mais especificamente para a escrita literária, conhecido normalmente como norma gramatical ou norma-padrão), seja por parte de grupos de usuários da língua (uma norma-padrão assumida por elites socioculturais para uniformizar a fala e, sobretudo, a escrita de prestígio; uma norma cuja idealização nem sempre coincide com a que fundamenta a norma-padrão gramatical, mas tende a dela se aproximar).

A segunda denominada pelo autor como norma subjetiva, implícita ou padrão real é a atitude que o falante assume perante a norma objetiva. Cabe o perfil daquilo que é normal, costumeiro, na prática das comunidades de fala, configurando, assim, efetivas variedades linguísticas. Nesse sentido, norma aqui corresponde ao conjunto de usos linguísticos mais produtivos, preferenciais na fala (e na escrita) de certos grupos de falantes. E a norma prescritiva é assumida pelo autor como a combinação entre o que ele chamou de norma objetiva e norma 
subjetiva, isto é, são os usos linguísticos da classe social de prestígio, identificados como o ideal de perfeição da linguagem.

O fato de pensarmos na existência de uma língua padrão afeta o modo como os falantes pensam sua própria língua e a língua em geral. Uma importante consequência da padronização da língua tem sido o desenvolvimento, entre os falantes, de uma "correta" ou canônica da língua. Segundo HORA (2011, p.20),

\begin{abstract}
Isto significa que todo som deva ser pronunciado da mesma forma por todos os falantes, que todos falantes devam usar as mesmas formas gramaticais e os mesmos itens lexicais. Isto também implica que a língua não possa sofrer mudança. Na verdade, o ideal da uniformidade absoluta nunca é alcançado. Embora a padronização não ratifique a variabilidade, nenhuma língua é completamente invariante.
\end{abstract}

Há um entrave entre o que propõem os estudos sociolinguísticos e o que pratica o professor de Língua Portuguesa. É preciso que o professor reflita sobre a norma em que vai se basear as suas atividades em sala de aula. Primeiro, porque os usos linguísticos recebem valores na sociedade, embora todos sejam cientificamente legítimos, mas há os que são avaliados como de prestígio (bonito, correto, agradável) e há os que são avaliados com estigma (feio, errado, desagradável). Segundo o quadro teórico sociolinguístico (LABOV, 2008[1972]), há fatos linguísticos que não recebem avaliação de determinada comunidade de fala e são usados inconscientemente; há outros que recebem avaliação positiva ou negativa dependendo do contexto em que estão inseridos; e outros, que sempre recebem avaliação negativa.

Ao professor, cabe conhecer o perfil das variantes com que lida diariamente nas produções de seus alunos, avaliar sua natureza e orientar os estudantes na busca da adequação dos textos que produzem em relação ao gênero e à situação interacional em que se encontram e no reconhecimento das variantes pouco familiares nos textos que leem e interpretam na sala de aula. É preciso que o professor domine um contínuo que, segundo Bortoni-Ricardo (2004, 2005, 2008), vai (i) do mais monitorado/formal ao menos monitorado/informal (contínuo de monitorização estilística); (ii) do mais rural ao mais urbano (contínuo de urbanização); e (iii) do mais oral ao mais escrito (contínuo de oralidade-letramento).

No papel que the foi confiado, cabe ao professor:

(i) dar orientações seguras nas atividades de produção textual, valendo-se das preferências pautadas nas efetivas normas de uso brasileiras faladas e escritas;

(ii) promover, nas atividades de leitura e de escrita dos mais diversos gêneros, o reconhecimento de usos linguísticos pouco familiares à comunidade de fala a que pertencem 
seus alunos, por serem esses usos pertencentes a outras variedades, prestigiadas ou não, ou, ainda, a outras sincronias.

Caso não se faça um trabalho efetivo de reconhecimento das diferentes normas linguísticas que convivem no contexto escolar e, principalmente, fora dele, procurando questionar por que, como e quando essas expressões linguísticas significam o que significam, o ensino de Língua Portuguesa pode acabar por considerar padrões de usos linguísticos absolutamente artificiais como o "certo", através de atividades repetitivas de metalinguagem que nada contribuem com a necessidade de ampliação das competências de leitura e produção de textos.

\section{A variação linguística, o ensino de língua portuguesa em sala de aula e o livro didático}

O fato de as línguas passarem por mudanças é algo que pode ser percebido de mais de uma forma. Uma delas é o contato com pessoas de outras faixas etárias, que possibilita acompanhar a mudança efetivada com o tempo. Quanto maior for a diferença de idade, maior a probabilidade de encontrarmos diferenças na forma de falar das pessoas, tanto no vocabulário, nas construções morfossintáticas, quanto na pronúncia diferente de certas palavras ou de certos sons.

Entendemos, assim, que a variação linguística está presente em toda língua e que toda língua tem e deve sofrer mudança. Mas, se a língua varia e tem que variar para se adaptar às mais diversas formas de interação, por que é tão complicado para os usuários da língua acreditar que essas variações são necessárias e que não são deturpações da língua? Infelizmente, há uma crença instaurada da supremacia da chamada língua-padrão, a língua, considerada boa, correta, de prestígio e que deve servir de parâmetro para o bom falar e escrever. Assim, o que foge a essa língua padrão, deve ser combatido, pois não é língua de prestígio, não é bom português.

No entanto, a norma-padrão não faz parte da língua, não corresponde a nenhum uso real da língua, constituindo-se muito mais como um modelo, uma entidade abstrata que exerce um grande poder simbólico sobre o imaginário dos falantes urbanos mais escolarizados (BAGNO, 2007p.106). Essa norma, portanto, serviu e serve ainda de referência para estimular o processo de uniformização, não podendo ser confundida com a língua em si, isto é, com a prática constitutiva das relações entre interlocutores. Pode-se deduzir que o conceito de variedade/norma-padrão em si mesmo não está ligado ao sistema linguístico propriamente, mas a uma ideologia. Milroy (2011, p.55) confirma: “De fato, a dicotomia padrão/não-padrão deriva, 
ela mesma, de uma ideologia - ela depende da aceitação prévia da ideologia da padronização e da centralidade da variedade padrão."

É mais do que justo que o professor explique com base em teorias linguísticas consistentes, a origem e o funcionamento das formas linguísticas consideradas não-padrão, que mostre as regras gramaticais que governam cada uma delas. Para tanto, ele deve receber uma formação científica muito boa, para contribuir com os falsos mitos e preconceitos sobre a língua. Isso deixará claro que as opções alternativas à norma-padrão tradicional não são caóticas nem confusas nem incoerentes: muito pelo contrário, obedecem a regras lógicas e consistentes quanto as que governam a opção padrão e por isso podem ser explicadas cientificamente.

Bagno (2002, p.75) afirma que

\begin{abstract}
uma das tarefas do ensino de língua na escola seria, então, discutir os valores sociais atribuídos a cada variante linguística, enfatizando a carga de discriminação que pesa sobre determinados usos da língua, de modo a conscientizar o aluno de que sua produção linguística, oral ou escrita, estará sempre sujeita a uma avaliação social, positiva ou negativa.
\end{abstract}

Bortoni-Ricardo (2004) ainda reconhece que cabe à escola levar os alunos a desenvolverem a competência de uso das variedades cultas da língua, mas ela não pode se eximir de fazer uma reflexão acerca da conflitante realidade que ainda vivenciamos. À escola ainda compete, sem dúvida, promover uma apreciação da norma-padrão, sempre com um olhar crítico.

Apesar disso, a escola e a sociedade não podem deixar de reconhecer a legitimidade do vernáculo utilizado por quem quer que seja; não podem, por outro lado, negar ou dificultar o acesso do aluno ao domínio das variedades linguísticas que ele desconhece. E precisa, para tanto, buscar instrumentos adequados. A formação do professor, não só de Língua Portuguesa, em Sociolinguística é condição fundamental, assim como a escolha do seu material didático de apoio.

Muitas vezes, o livro didático é o único apoio fundamental que os professores têm para economizar tempo de planejamento e organizar melhor os conteúdos a serem ministrados em sala de aula. Assim, torna-se um valioso recurso para o acesso à cultura e o desenvolvimento da educação. Em muitos lares brasileiros, ele é o primeiro livro, abrindo caminho para o hábito da leitura e o aprendizado. E, por isso, o livro didático é importante instrumento de apoio ao trabalho do Professor e referência na formação de várias crianças, adolescentes e adultos matriculados em escolas públicas e privadas 
Segundo Libâneo (2002), o livro didático é um recurso importante na escola por ser útil tanto ao professor como ao aluno, pois através dele o docente pode reforçar seus conhecimentos sobre um assunto específico ou receber sugestões de como apresentá-lo em sala de aula. Já para o aluno, é uma forma de ter de maneira mais organizada e sistematizada um assunto que possibilite que ele revise em sua casa e faça exercícios que reforcem este conhecimento.

A decisão de fazer do livro didático um aliado ou um inimigo parte do professor em relação às escolhas que faz no seu dia a dia. Segundo Lajolo (1996), se é notório que o livro didático apresenta problemas tanto em erros conceituais como também preconceitos dos mais diversos, por outro lado pode ajudar os alunos a formarem conceitos e elaborarem suas próprias estratégias cognitivas. Portanto, para o professor de Língua Portuguesa, a concepção que ele tem de língua norteará todo o seu trabalho pedagógico em sala de aula, assim como a escolha do Livro Didático, que o acompanhará durante anos.

\section{A variação linguística e o livro didático}

A nossa opção pela análise dos livros didáticos se justificou pela necessidade de pesquisar como se encontra a variação linguística em livros didáticos que passam pelo crivo do MEC, tema que parece ser debatido a exaustão em vários trabalhos de cunho sociolinguístico, mas que ainda, em pleno século XXI, se mostra um desafio para professores e para as aulas de Língua Portuguesa. A escolha também pelos livros, Jornadas.port e Singular \& Plural: Leitura, produção e estudos de linguagem, de autores diferentes, deu-se com o propósito de se observar a existência ou não de diferenças de visão dos autores sobre a variação linguística.

Foi verificado o manual do professor, por ser um instrumento didático que pode fornecer subsídios para atualização e formação do professor, com o intuito de observar de que forma esse manual trata a variação linguística e se esclarece ao professor a maneira de abordála em sala de aula.

A pesquisa é constituída de um trabalho bibliográfico/documental e está inserida no campo da Sociolinguística, área que trata especificamente das relações entre língua e sociedade. No caso da nossa pesquisa, esta terá uma abordagem qualitativa, buscando, pois, analisar o tratamento dado à variação linguística nos livros didáticos mencionados.

O fato de se eleger o livro didático como objeto de análise se deu em função de se caracterizar como um instrumento didático que exerce grande influência na prática pedagógica 
de professores, chegando-se ao ponto de ser determinado por esse instrumento o 'que ensinar' e o 'como ensinar', como já vimos.

A fim de observar livros didáticos destinados e distribuídos do $6^{\circ}$ ao $9^{\circ}$ ano do Ensino Fundamental II da rede pública estadual de ensino, separamos duas coleções de Língua Portuguesa, aprovadas pelo Programa Nacional de Livro Didático (PNLD). Foram selecionados os livros do $6^{\circ}$ e do $7^{\circ}$ anos porque é nessas séries/anos que se concentram capítulos e/ou unidades dedicados à variação linguística. Para realização da análise proposta, utilizamos os livros das duas coleções elencadas já referidas:

COLEÇÃO 1 - Jornadas.port - Língua Portuguesa $7^{\circ}$ ano, de Dileta Delmanto e Laiz B. de Carvalho (2012).

COLEÇÃO 2 - Singular \& Plural: Leitura, produção e estudos de linguagem $6^{\circ}$ ano, de Laura de Figueiredo, Marisa Balthasar e Shirley Goulart.

A nossa análise se pautará no seguinte roteiro proposto nos estudos de Bagno (2007, p.125):

1. O livro didático trata da variação linguística?

2. O livro didático menciona de algum modo a pluralidade de línguas que existe no Brasil?

3. O tratamento se limita às variedades rurais e/ou regionais?

4. O livro didático apresenta variantes características das variedades prestigiadas (falantes urbanos escolarizados)?

5. O livro didático separa a norma-padrão da norma culta (variedades prestigiadas) ou continua confundindo a norma padrão com uma variedade real da língua?

6. O tratamento da variação no livro didático fica limitado ao sotaque e ao léxico, ou também aborda fenômenos gramaticais?

7. O livro didático mostra coerência entre o que se diz nos capítulos dedicados à variação linguística e ao tratamento que dá aos fatos de gramática? Ou continua, nas outras seções, a tratar do "certo" e do "errado"?

8. O livro didático também explicita que também existe variação entre fala e escrita, ou apresenta a escrita como homogênea e a fala como lugar do erro?

9. O livro didático aborda o fenômeno da mudança linguística? Como? 10. O livro didático apresenta a variação linguística somente para dizer que o que vale mesmo, no fim das contas, é a norma-padrão?

Então, a partir daqui, retomaremos cada uma das questões para discuti-las em relação aos livros didáticos selecionados.

QUESTÃO 1: O Livro Didático trata da Variação Linguística?

QUADRO 1: Resposta da Questão 1

\begin{tabular}{|l|l|}
\hline COLEÇÃO 1 & $\begin{array}{l}\text { O livro do } 7^{\circ} \text { ano aborda a variação linguística na seção Reflexão sobre a língua nas páginas 145 } \\
\text { a 153; } 162 \text { a } 168 .\end{array}$ \\
\hline COLEÇãO 2 & $\begin{array}{l}\text { O livro do } 6^{\circ} \text { ano aborda a variação linguística na unidade 1 Língua e Linguagem, pág. 190. E na } \\
\text { unidade 2: A língua como um conjunto de variedades, pág. 210. }\end{array}$ \\
\hline
\end{tabular}


A variação linguística é um tema muito debatido na atualidade, mas, apesar de inúmeros trabalhos acadêmicos e científicos sobre o tema, a escola ainda encontra resistência em abarcar, em seus bancos, variedades oriundas das classes menos favorecidas da sociedade. $\mathrm{Na}$ verdade, a própria sociedade não aceita, tampouco estimula a abertura escolar para essas variantes.

Em relação à primeira questão, os dois livros didáticos observados abordam a questão variacionista da língua portuguesa. Na coleção 1, no livro do $7^{\circ}$ ano, as autoras trabalham com as variedades linguísticas: regionais, históricas e socioculturais, variações de registro. Para introduzir o assunto, o livro inicia um trabalho com alguns textos de cordel, falando da métrica dos poemas e de seus autores. Em seguida, partindo de textos de diferentes gêneros textuais, identificam-se as marcas linguísticas que singularizam as variações históricas, regionais e de registro. Já a coleção 2 trata da variação linguística no livro do $6^{\circ}$ ano, partindo de uma diversidade de gêneros textuais para falar das mudanças que ocorrem na língua, ou seja, a variação histórica. A coleção trata também das variedades urbanas de prestígio, da língua enquanto identidade e do registro formal e informal dentro de uma situação de comunicação. Em seguida, traz uma quantidade expressiva de atividades sobre o assunto.

QUESTÃO 2: Ele menciona a pluralidade de línguas que existe no Brasil?

QUADRO 2: Resposta da Questão 2

\begin{tabular}{|l|l|}
\hline COLEÇÃO 1 & $\begin{array}{l}\text { O livro do } 7^{\circ} \text { ano na pág.145 traz um mapa com os países que falam } \\
\text { português além do Brasil. Tratam da diferença entre o português brasileiro } \\
\text { e o europeu (Portugal), através de uma HQs da personagem Calvin. }\end{array}$ \\
\hline COLEÇÃO 2 & $\begin{array}{l}\text { O livro do } 6^{\circ} \text { ano não traz nenhuma referência à pluralidade de línguas } \\
\text { existente no Brasil }\end{array}$ \\
\hline
\end{tabular}
Fonte: Os autores.

Em relação à segunda questão, observamos que a primeira coleção traz um box em que se comenta que somos um país de muitas línguas além da Língua Portuguesa. E que no Brasil, além do português - o idioma oficial -, existem cerca de 180 outras línguas, sem considerar as comunidades de imigrantes, só as dos indígenas. Foi a única referência à pluralidade de língua que existe no Brasil. Na coleção 2, o livro didático não faz nenhuma menção a pluralidade de línguas existente no Brasil.

Para Bagno (2007, p.128), 
O plurilinguismo brasileiro sempre foi silenciado, inclusive por meio de ações violentas como proibições formais, massacres de povos indígenas etc. É uma pena que toda essa história permaneça oculta e que a escola continue preservando o mito do monolinguismo.

Como comprovamos, a asserção do autor é ratificada nas duas coleções, o que nos leva a reforçar a necessidade de se retratar o aspecto histórico das línguas.

QUESTÃO 3: O tratamento se limita às variedades rurais e/ou regionais?

QUADRO 3: Resposta da Questão 3

\begin{tabular}{|l|l|}
\hline COLEÇÃO 1 & $\begin{array}{l}\text { O livro faz uma menção muito ínfima em relação à variedade regional, ao comentar as dimensões } \\
\text { territoriais do Brasil. Faz também menção às variações socioculturais e situacionais. }\end{array}$ \\
\hline COLEÇÃO 2 & $\begin{array}{l}\text { O livro parte de uma infinidade de atividades com alguns gêneros textuais para discutir algumas } \\
\text { variações que a língua portuguesa apresenta. }\end{array}$ \\
\hline
\end{tabular}
Fonte: Os autores.

As coleções trazem em suas páginas algumas variedades linguísticas para serem trabalhadas com o aluno. A coleção 1 traz um pequeno texto para fazer referência à variedade linguística das regiões Norte e Nordeste, porém sem muito aprofundamento. Em seguida faz referência às variedades históricas através do poema Antigamente, de Carlos Drummond de Andrade. Na página 162, traz as variações socioculturais decorrentes da idade dos falantes, utilizando-se do fragmento da crônica Modos de xingar, também de Carlos Drummond de Andrade; para falar da variação situacional (variação de registro), e mais uma vez, a coleção faz uso do poema Aula de Português, do poeta Carlos Drummond de Andrade, para iniciar uma atividade a respeito de formalidade e informalidade ao se utilizar a língua.

Na página 169, para finalizar o assunto, a coleção faz uso, em uma proposta de atividade do Enem, que trabalha com a variedade linguística, da tirinha do Chico Bento. Segundo Bagno (2013, p.83):

O problema dessas opções é que as revistas do Chico Bento, as canções de Adoniran e Luís Gonzaga e os poemas de Patativa não são representações fiéis das variedades linguísticas que eles supostamente veiculam. Não são, nem têm que ser, já que em todas essas manifestações está presente uma intenção lúdica, artística, estética e, nem de longe, um trabalho científico rigoroso. O problema está no uso inadequado que se faz dos trabalhos criativos dessas pessoas. 
Seria muito mais interessante fazer o aluno reconhecer que a língua é, sim, heterogênea e variável, inclusive na fala e na escrita das pessoas escolarizadas - jornalistas, escritores, médicos, juristas etc. - sem nenhum vínculo com a cultura rural.

Para tratar da variedade rural, a coleção 2, na pág. 213, traz uma tirinha em que a personagem Mutum, que mora na cidade, vai visitar sua tia, que mora em um sítio muito afastado da cidade. Na conversa entre Mutum e sua tia, há uma má interpretação por parte da tia de Mutum em relação à palavra "fartura", que ela entendeu como "faltando" algo, criando uma confusão por parte da variedade utilizada pela tia da personagem da tirinha. E na pág. 215, o livro traz um poema de cordel para também fazer referência à variação linguística. A partir desses gêneros textuais e de suas situações comunicativas, são feitos os questionamentos entre variedade padrão, de prestígio e variedade rural/caipira. A análise dos fenômenos variáveis do português brasileiro nos LDs recai, quase sempre, sobre algumas realizações fonéticas.

QUESTÃO 4: O Livro Didático apresenta variantes características das variedades prestigiadas (falantes urbanos, escolarizados)?

QUADRO 4: Resposta da Questão 4

\begin{tabular}{|l|l|}
\hline COLEÇÃO 1 & $\begin{array}{l}\text { O livro faz referência à norma-padrão e às variedades urbanas de prestígio na pág. 150, fazendo } \\
\text { uma correlação, num grande equívoco, entre variedades urbanas de prestígio e norma-padrão }\end{array}$ \\
\hline COLEÇÃO 2 & $\begin{array}{l}\text { O livro traz uma nota explicativa em relação a variedades e preconceito linguístico. Partindo de } \\
\text { uma atividade com tirinha. }\end{array}$ \\
\hline
\end{tabular}
Fonte: $\mathrm{O}$ autor.

A coleção 1, na pág. 145, inicia falando das variedades regionais entre o português do Brasil e o de Portugal. Na pág. 147, trata do português do Brasil e o português de países africanos. Em seguida, fala das variedades linguísticas em várias regiões do país, como a região norte ou nordeste, e de como as pessoas falam de modo diferente da região sul. E que a época também determina a variedade linguística a ser utilizada. Traz a norma-padrão como garantia de uma estabilidade na língua, ou seja, para que não se transforme num caos a comunicação entre as pessoas. Sendo vista como uma espécie de modelo ideal de língua, que pode orientar os falantes quando precisarem usar a língua de modo mais formal e lhes permitir acessar um universo de informações registradas em livros, jornais, documentos oficiais etc. Na pág. 150, o livro comenta sobre as variedades urbanas de prestígio, mas faz uma comparação com a norma padrão, equivocando-se duas formas diferentes de apresentação. Em seguida, na pág. 151, traz uma atividade baseada no poema de Oswald de Andrade intitulado Vício na fala, com perguntas relacionadas à norma-padrão, numa tentativa de reescrita do poema para uma norma-padrão. Ou seja, por causa do prestígio socialmente conferido à fala dos cidadãos urbanos mais letrados, 
fica a ilusão de que eles se comportam linguisticamente de acordo com as prescrições da gramática normativa. Isso se revela na confusão terminológica entre "norma culta" e "normapadrão". Mais uma vez, o poema que poderia servir de apoio para reflexões acerca do preconceito linguístico em relação a variantes estigmatizadas, na atividade sugerida pelas autoras do livro, fica resumido a questões de reescrita para a norma-padrão. A coleção traz um box em que se procura responder à seguinte pergunta: Por que estudar a norma-padrão na escola? Como justificativa para se cobrar tanto a uniformização da língua, numa valorização à norma-padrão veiculada nas gramáticas normativas, o livro traz as seguintes respostas: "Para que os falantes de variedades desprestigiadas consigam utilizar serviços a que têm direito e possam compreender a linguagem empregada pelos órgãos públicos, nos contratos, nos documentos jurídicos" (p. 151). Outro motivo: "Dominar a norma-padrão permite acessar o conhecimento acumulado por muitas gerações; permite compreender e redigir textos literários, didáticos, técnicos, científicos, jornalísticos; permite sair-se bem em situações relativas a trabalho, concursos e provas" (p. 151).

A coleção 2 traz, na seção sobre variedades linguísticas, três textos com a finalidade de que o aluno observe as mudanças da língua no tempo (variação histórica ou diacrônica) e os quatro últimos textos possibilitam a observação das variações da língua num mesmo tempo (variação sincrônica), mas em espaços sociais / regiões diferentes (variação diatópica); grupos sociais (variação diastrática) e situações de comunicação (variação diafásica).

Para falar das variedades da língua e preconceito linguístico, a coleção trabalha com a tirinha de Urbanóide e a tirinha de Mutum. A primeira (do Urbanóide) trata de uma conversa entre duas pessoas, uma carioca e a outra paulistana. Só que a carioca critica o modo de falar da paulistana, dizendo que ela tem um sotaque muito "estranho". Na segunda tira, a personagem Mutum, que leva o nome da tira, mora na cidade e vai visitar a tia, que mora bem distante do centro da cidade. Na hora do almoço, o sobrinho fala para a tia muito alegre: “Nossa, tia! Que fartura!", pois a mesa estava cheia de comida. A tia fica chateada, pois reclama com o sobrinho a respeito do que estava "fartando" na mesa. As atividades propostas pela coleção levam à discussão entre variedades urbanas de prestígio e preconceito linguístico em relação às falas das personagens das tirinhas. Segundo as autoras, as falas que se aproximam da norma-padrão são vistas e analisadas como positivas, boas, pois são faladas pelas classes sociais que vivem nas grandes cidades e que têm maior poder econômico e grau de escolaridade, ou seja, são as variedades urbanas de prestígio. E espera-se dos usuários da língua que façam uso dessas variedades porque são as que a sociedade sempre valorizou. 
É nítida a tendência em tratar erroneamente a variação linguística como sinônimo de variedades regionais, rurais ou de pessoas não escolarizadas. Parece que os falantes urbanos e escolarizados usam a língua de um modo mais uniforme, mais "correto", mais próximo do padrão, e que nesse uso não existe variação. E, quando há, é atribuída à informalidade, o que é um tremendo equívoco de análise.

Para Bagno (2007, p. 129):

\begin{abstract}
essa é uma pergunta que, infelizmente, até agora, só tem podido ser respondida de forma negativa. Mesmo os livros didáticos que conseguem tratar da variação linguística de maneira relativamente satisfatória acabam deixando de lado as variedades urbanas. Por causa do prestígio socialmente conferido à fala dos cidadãos urbanos mais letrados, fica a ilusão de que eles se comportam linguisticamente de acordo com as prescrições da gramática normativa.
\end{abstract}

QUESTÃO 5: O livro didático separa a norma-padrão da norma culta (variedades prestigiadas) ou continua confundindo a norma-padrão com uma variedade real da língua?

QUADRO 5: Resposta da Questão 5

\begin{tabular}{|l|l|}
\hline COLEÇÃO 1 & $\begin{array}{l}\text { As autoras não utilizam o termo norma culta. No livro do } 7^{0} \text { ano na pág. 150, as autoras falam } \\
\text { da norma-padrão e das variedades urbanas de prestígio. Na pág. 151, as autoras explicam em } \\
\text { um pequeno texto o porquê de se estudar a norma-padrão na escola. Segundo elas, um dos } \\
\text { motivos é que indivíduos de variedades desprestigiadas deixam de usufruir de serviços públicos } \\
\text { porque não "compreendem a linguagem empregada", e outro motivo seria o acesso ao } \\
\text { "conhecimento acumulado por muitas gerações; permite compreender e redigir textos literários, } \\
\text { didáticos, técnicos, científicos, jornalísticos; permite sair-se bem em situações relativas a } \\
\text { trabalho, concursos e provas." }\end{array}$ \\
\hline COLEÇÃO 2 & $\begin{array}{l}\text { O livro trata das variedades urbanas de prestígio na pág. 214, sem fazer referência a diferença } \\
\text { entre as normas padrão e culta. }\end{array}$ \\
\hline
\end{tabular}

Fonte: Os autores.

Na coleção 1, as autoras utilizam o termo norma-padrão e variedades urbanas de prestígio. O LD traz uma definição de norma-padrão como um modelo ideal da língua, um conjunto de regras que garante a ela uma relativa estabilidade. As autoras fazem uma confusão ao dizer que as variedades de prestígio recebem esse nome por se aproximarem da normapadrão. Para Bagno (2013, p. 63), a norma-padrão, de fato, está longe de ser uma "variedade", um "dialeto" ou uma "língua", no sentido de um sistema fonomorfossintático que se realiza na fala dos indivíduos, mas que:

é "uma ideia na mente", uma ideologia linguística, uma instituição social e, nessa qualidade,

$>$ goza de um poder simbólico particular, muito diferente do que se atribui às autênticas variedades linguísticas; 
ocupa no imaginário coletivo um lugar de destaque, um posto superior no ideário linguístico;

$>$ é objeto de um culto e de um cultivo que ninguém jamais dedica com a mesma intensidade aos outros modos (reais) de falar.

E é precisamente por isso que a norma-padrão não pode ser confundida com a norma culta, isto é, o conjunto de variedades urbanas de prestígio realmente empregadas pelas camadas privilegiadas da população.

A coleção 1 não faz a separação entre norma-padrão e norma culta, uma vez que as autoras não fazem referência à norma culta.

A coleção 2 não cita a norma-padrão. O livro trabalha com variedades urbanas de prestígio, fazendo referência à norma culta utilizada pelas pessoas escolarizadas e que ocupam uma posição na sociedade. Devemos ficar atentos, uma vez que norma-padrão não pode ser confundida com a norma culta, isto é, o conjunto de variedades urbanas de prestígio realmente empregadas pelas camadas privilegiadas da população.

Para Faraco \& Zilles (2017, p. 19):

\begin{abstract}
a norma culta designa-se tecnicamente o conjunto das características do grupo de falantes que se consideram cultos (ou seja, a "norma normal" desse grupo social específico). Na sociedade brasileira, esse grupo é tipicamente urbano, tem elevado nível de escolaridade e faz amplo uso dos bens da cultura escrita. A chamada norma culta é uma "norma normal", porque é uma das tantas normas presentes na dinâmica corrente, viva, do funcionamento social da língua.
\end{abstract}

Na pesquisa sociolinguística, só podemos rotular um modo de falar como língua, variedade ou dialeto quando é possível identificar empiricamente um grupo social que de fato fale essa língua, variedade ou dialeto. Ninguém no Brasil efetivamente fala a norma-padrão, não existem "falantes do padrão", embora os livros didáticos insistam em dizer que sim.

Segundo Bagno (2013, p. 62):

\begin{abstract}
A norma-padrão definitivamente não é uma das muitas variedades linguísticas que existem na sociedade. Não existe uma variedade padrão (aliás, uma contradição em termos, pois se é padrão, isto é, uniforme e invariante, como pode ser uma "variedade"?), nem um dialeto padrão, nem uma língua padrão. O que existe é uma norma-padrão, língua materna de ninguém, uma norma no sentido mais jurídico do termo.
\end{abstract}

A confusão entre a língua realmente empregada pelos falantes urbanos escolarizados e o padrão estabelecido nas gramáticas normativas está presente nas obras pesquisadas. Para Bagno (2013), a norma-padrão é uma 'receita de língua', não é uma língua nem uma variedade real. 
QUESTÃO 6: O tratamento da variação no livro didático fica limitado ao sotaque e ao léxico, ou também aborda fenômenos gramaticais?

QUADRO 6: Resposta da Questão 6

\begin{tabular}{|l|l|}
\hline COLEÇÃO 1 & $\begin{array}{l}\text { O livro traz as diferenças entre o português do Brasil e o de Portugal. Traz também um mapa onde } \\
\text { se pode localizar os países que falam português }\end{array}$ \\
\hline COLEÇÃO 2 & $\begin{array}{l}\text { O livro traz muitas atividades onde se trabalha com os diferentes falares. Traz dois boxes } \\
\text { comentando sobre diferentes pronúncias dos sons da fala e troca de letras e sons nas palavras. }\end{array}$ \\
\hline
\end{tabular}
Fonte: Os autores.

A coleção 1 inicia com um trecho da crônica A língua de Rubem Braga, a respeito do falar do Brasil e de Portugal. Em seguida, traz um mapa mostrando os países que falam a língua portuguesa para tratar da variação linguística entre o falar do Brasil e o falar de Portugal, porém sem se aprofundar nas questões mais importantes para o ensino. A comparação entre o português brasileiro e o português europeu teria como principal utilidade demonstrar a distância que separa as gramáticas das duas línguas. Muito frequente é o tratamento da variação se limitar a comparar sotaque e léxico do português brasileiro e do português europeu, sem se aprofundar nas questões mais importantes para o ensino no Brasil e transformando a variação linguística, ainda que involuntariamente, numa lista de coisas engraçadas e curiosas, uma espécie de anedotário. É sabido que o sotaque e o léxico devem ser abordados nas coleções como fenômenos de variação linguística. Sabemos que o preconceito linguístico entra em ação no momento que alguém abre a boca para falar e exibe pronúncias e palavras características de uma região ou de uma classe social desprestigiada.

A coleção 2, na pág. 214, traz dois boxes com explicações sobre a pronúncia diferente dos sons das palavras, para tratar do sotaque e para falar de como a troca de letras e sons nas palavras pode determinar o grupo social de uma pessoa. Na pág. 217 , trabalha com a tirinha do Tapejara, para mostrar a variedade linguística utilizada por um gaúcho.

É muito frequente, nos LDs, a abordagem da variação linguística se restringir a fenômenos referentes ao sotaque e ao léxico de forma um tanto vaga. Assim como, abordarem a variação linguística afirmando que "um gaúcho não fala como um pernambucano, um carioca não fala como um paulistano". Recurso muito presente também é o mapa do Brasil com balões de história em quadrinho exibindo expressões, interjeições ou vocabulário característico de alguns estados: "uai", "tchê", "oxente" etc.

É claro que sotaque e léxico também devem ser abordados como fenômenos de variação linguística. Pois, é sabido que o preconceito linguístico entra em ação imediatamente 
quando alguém abre a boca para falar e exibe pronúncias e palavras características de uma região ou de uma classe social desprestigiada.

QUESTÃO 7: O livro didático mostra coerência entre o que diz nos capítulos dedicados à variação linguística e o tratamento que dá aos fatos de gramática? Ou continua, nas outras seções, a tratar do "certo" e do "errado"?

QUADRO 7: Resposta da Questão 7

\begin{tabular}{|l|l|}
\hline COLEÇÃO 1 & $\begin{array}{l}\text { Segundo às autoras, no Manual do Professor, o livro tem como meta aumentar a competência } \\
\text { comunicativa do aluno, levando-o a conhecer, reconhecer e empregar adequadamente os recursos } \\
\text { da língua em seus vários níveis, no que diz respeito tanto a suas regras gerais como aos elementos } \\
\text { que interferem no contexto de uma situação comunicativa. }\end{array}$ \\
\hline COLEÇÃO 2 & $\begin{array}{l}\text { Segundo às autoras, no Manual do Professor, o livro tem como pressuposto teórico-metodológico } \\
\text { as teorias de aprendizagem socioconstrutivista. Tomando a linguagem como atividade discursiva, } \\
\text { o texto como unidade de ensino e a noção de gramática como relativa ao conhecimento que o } \\
\text { falante tem de sua linguagem. }\end{array}$ \\
\hline
\end{tabular}

Fonte: Os autores.

As coleções abordam a variação linguística em seus capítulos. A coleção 1, a partir da Unidade 4, trazendo como abertura para falar da variação, trabalha com os gêneros: a poesia de cordel e causo. Ou seja, as autoras ainda pensam que a variedade linguística tem de estar ligada ao falar do nordestino ou da roça, como se somente as pessoas nordestinas ou da roça usassem a variação, é como se ela acontecesse somente nesses locais, mas não é bem assim que as pesquisas de cunho sociolinguística mostram. A variedade linguística é trabalhada nesse capítulo com a utilização de bastantes poemas de cordelistas, tirinhas, música de Luiz Gonzaga e poema de Carlos Drummond de Andrade. O livro trabalha com a variedade linguística como se fosse um conteúdo, apenas num capítulo do livro. Em seguida, o livro parte para uma abordagem puramente prescritivista. Trabalhando com acentuação das oxítonas, tipos de frase e oração e em seguida com os tipos de sujeito. A gramática normativa é apresentada de forma mais sutil, dentro de um texto, mas não deixa de ser valorizada com suas regras e normas.

A coleção 2, em sem Manual do Professor, parte do pressuposto de que o ensino de língua materna na escola inicia-se com um trabalho das variedades urbanas de prestígio e deve se dá partindo da própria linguagem e dos gêneros textuais de que os alunos se utilizam em seu meio social fora da escola. Nas aulas de Língua Portuguesa, o fortalecimento da cidadania pode ser alcançado de várias formas: uma delas é abordar, ao mesmo tempo, questões de variação linguística e trabalhar as variedades urbanas de prestígio. E para tentar atingir seus objetivos, no capítulo 2, a coleção começa a tratar da variedade linguística, partindo de um anúncio de 1821, de 2014 e um poema de 1928, para falar da variação da língua no tempo. Em seguida, na 
unidade 2, o livro trabalha com língua e gramática normativa, ou seja, o livro começa a tratar de forma prescritivista, contradizendo o que propõe no Manual do Professor.

As duas coleções tratam das questões referentes à variação linguística em apenas um capítulo ou unidade do livro. É como se os Livros Didáticos só abordassem a variação linguística para cumprir as exigências do Ministério da Educação e poder entrar na lista das obras que vão ser compradas e distribuídas. A variedade linguística é tratada de forma "politicamente correta" no dizer de Bagno(2013). Partindo de uma atitude nada preconceituosa, com uso de diversos gêneros textuais, respeitando as variedades linguísticas. Porém, o restante do livro há questões gramaticais abordadas de maneira bastante conservadora. Segundo Bagno (2007, p.135):

É incoerente pedir respeito e tolerância diante da variação linguística e dizer, nos exercícios de gramática, que usar o pronome ELE como objeto direto é um "erro", ou que o pronome você é apenas "forma de tratamento", ou que é "proibido" iniciar frases com pronome oblíquo, ou que não se pode dizer EU CUSTO A CRER, mas somente CUSTA-ME CRER... [...]

Essa incoerência decorre, muitas vezes, da tendência de considerar variação linguística como sinônimo de "fala popular" ou "rural", esquecendo que nas atividades linguísticas dos falantes urbanos letrados também ocorre variação e que a heterogeneidade da língua falada também existe na língua escrita.

QUESTÃO 8: O livro didático explicita que também existe variação entre fala e escrita ou apresenta a escrita como homogênea e a fala como lugar do erro?

QUADRO 8: Resposta da Questão 8

\begin{tabular}{|l|l|}
\hline COLEÇÃO 1 & $\begin{array}{l}\text { O livro didático do } 6^{\circ} \text { ano não faz nenhum comentário sobre a diferença entre a fala e a escrita. } \\
\text { Porém, na pág. } 165 \text { traz duas atividades que versam a respeito da diferença entre a fala e a escrita. }\end{array}$ \\
\hline COLEÇÃO 2 & O livro didático do $7^{\circ}$ ano faz nenhum comentário sobre a diferença entre a fala e a escrita. \\
\hline
\end{tabular}

Fonte: Os autores.

As duas coleções tratam da variedade linguística como um todo, sem fazer uma especificidade entre a língua falada e a língua escrita. As coleções apresentam as variedades linguísticas e como elas se comportam em cada situação de comunicação e para isso, trabalha com alguns gêneros textuais.

Na coleção 1, há um fragmento de um texto escrito pelo humorista Jô Soares que retrata a diferença entre a língua falada e a língua escrita. Em seguida, a coleção traz mais uma atividade a respeito da diferença entre a fala e a escrita. Porém, essa diferença é pouca comentada. 
Na coleção 2, não há comentários sobre a diferença entre a fala e a escrita. A coleção traz informações a respeito da linguagem formal e informal. Ao tratar da língua oral e da língua escrita, reporta-se à situação de comunicação para se fazer uso de tais modalidades.

QUESTÃO 9: O Livro Didático aborda o fenômeno da mudança linguística? Como?

QUADRO 9: Resposta da Questão 9

\begin{tabular}{|l|l|}
\hline COLEÇÃO 1 & $\begin{array}{l}\text { No livro didático do } 6^{\circ} \text {, as autoras falam sobre as mudanças linguísticas no Unidade } 4 \text { nas págs. } \\
145 \text { a } 152 ; \text { e retomam o assunto nas págs. } 162 \text { a } 169 .\end{array}$ \\
\hline COLEÇÃO 2 & $\begin{array}{l}\text { No livro didático do } 7^{\circ} \text { ano, as autoras falam sobre as mudanças linguísticas no capítulo } 2 \text { nas } \\
\text { págs. } 210 \text { a } 223 .\end{array}$ \\
\hline
\end{tabular}
Fonte: Os autores.

As duas coleções falam a respeito do fenômeno da variação linguística. Cada uma de uma forma bem peculiar. Na coleção 1, o fenômeno da variação linguística é tratado através da utilização de alguns gêneros textuais. Na pág. 146, partindo da crônica Antigamente, de Carlos Drummond de Andrade, o livro didático trabalha com o vocabulário e a ortografia, a partir da variedade histórica. Encontra-se na coleção atividades sobre as variedades regionais, variedades históricas, variedades socioculturais, variação situacional, as variedades urbanas de prestígio e a norma-padrão. Na coleção 2, também se encontra uma quantidade de atividades referentes à variação linguística. A variação linguística é trabalhada, partindo de alguns gêneros textuais, ou seja, fala-se da variação histórica, variação urbana de prestígio, preconceito linguístico, variedade situacional, assim como linguagem formal e informal.

O estudo da variação linguística é fundamental, porque nos ajuda a compreender o fenômeno da mudança linguística. Infelizmente, alguns livros didáticos, como os analisados, abordam o fenômeno da mudança, mas quase nunca avançam no sentido de esclarecer que a mudança não parou, que a língua continua se transformando e que no futuro ela será diferente do que é hoje.

Bagno (2007, p.137) tece uma crítica em relação à abordagem que alguns LDs fazem no tratamento da variação. Para o linguista "é muito frequente limitar a abordagem da mudança às questões de vocabulário. Para tanto, esses livros costumam trazer a crônica Antigamente, de Carlos Drummond de Andrade, para tratar de palavras e expressões que não são mais usadas hoje em dia. Seria muito bom se os livros começassem a dar exemplos de textos antigos para mostrar que a língua mudou, não só no léxico, mas principalmente na sua gramática, nas regras que fazem a língua funcionar como funciona". 
QUESTÃO 10: O livro didático apresenta a variação linguística somente para dizer que o que vale mesmo, no fim das contas, é a norma-padrão?

QUADRO 10: Resposta da Questão 10

\begin{tabular}{|l|l|}
\hline COLEÇÃO 1 & $\begin{array}{l}\text { O livro didático trabalha com a variedade linguística e há algumas atividades de reescrita para a } \\
\text { norma-padrão. Pág. 151 e 152. }\end{array}$ \\
\hline COLEÇÃO 2 & $\begin{array}{l}\text { O livro didático trabalha com a variedade linguística e com atividades de reescrita para a norma- } \\
\text { padrão. Págs. 215 e 216. }\end{array}$ \\
\hline
\end{tabular}

Fonte: Os autores.

As duas coleções pesquisadas trabalham com a reescrita em suas atividades. Ao trabalhar com a variedade linguística em suas páginas, pede para reescrever na variedade padrão da língua.

Essa é uma forma muito sutil de preconceito linguístico, uma vez que ao abordar uma variedade linguística, o LD mostra que a língua não é homogênea como a gramática normativa pensa, mas que a língua é heterogênea e que essas mudanças são naturais e recorrentes das línguas, como forma de uma sobrevivência. No entanto, se depois de uma abordagem heterogênea, o livro didático mandar reescrever numa norma-padrão o que se encontra numa variedade totalmente adequada à situação de comunicação, ele se torna um instrumento extremamente rigoroso, rígido e conservador da chamada norma-padrão.

Não somos contrários ao ensino da chamada norma-padrão, mas é interessante se pensar até quando um ensino centrado apenas nessa norma pode tornar o aluno leitor e produtor de textos proficientes, uma vez que essa norma-padrão não faz parte do espectro contínuo de variedades linguísticas reais, efetivamente usadas numa comunidade. Ora, ninguém no Brasil efetivamente fala a norma-padrão, não existem "falantes do padrão", embora os livros didáticos insistam em dizer que sim.

\section{Considerações finais}

Nas obras analisadas, percebemos que o tratamento referente à variedade linguística é bastante folclorizado, principalmente, na variação geográfica, estereotipando os falares rurais. Deixam de fora dos estudos a variação social que é, de fato, a verdadeira questão a ser enfrentada, já que ela serve de critério para os gestos de discriminação dos falantes e de violência simbólica.

Além de equivocado, superficial e nada propício, o tratamento da variação linguística não leva o aluno/aprendiz a perceber o que de fato está em jogo nessas complexas relações 
entre língua/sociedade. Os principais problemas detectados na análise do tratamento da variação linguística nas coleções foram:

$>$ a falsa sinonímia norma-padrão = norma culta;

$>$ a falsa sinonímia norma-padrão = variedades urbanas de prestígio;

$>$ a classificação do padrão como uma variedade;

$>$ a redução do fenômeno de variação linguística às variedades rurais, "caipiras" ou de falantes poucos escolarizados;

$>$ a proposta de reescrita para a norma-padrão;

> as coleções tratam da variação de ordem diatópica e diacrônica, sem comentar a variação que acontece diariamente, que se relaciona a questões de ordem social, etária e genérica;

$>$ o trabalho com a variação linguística de modo estereotipado, contribuindo para a manutenção do discurso sobre o certo e o errado na língua;

> a variação linguística deveria estar presente em todas as unidades/capítulos do livro, até quando se abordasse a gramática normativa.

Isso não quer dizer que os LDs pesquisados são ruins. Eles são bons livros, uma vez que passaram pelo crivo de especialistas do PNLD 2012 para poder estar nas escolas, e porque se constituem em um material recomendável para o ensino de Língua Portuguesa. Sabemos também que não existe nenhuma coleção perfeita. Contudo, é importante salientar que, sem uma sólida formação acadêmico-científica e um conhecimento adequado da Sociolinguística por parte do professor de Língua Portuguesa, o livro didático sozinho, por mais bem elaborado que seja, não conseguirá resultar em um ensino/aprendizagem de língua materna que respeite a diversidade linguística dos falantes. Por isso, o que faltar ou falhar nessas coleções, é papel do professor suprir com pesquisas, estudos e materiais adequados para conseguir com que seu aluno apreenda e compreenda o conteúdo da melhor maneira possível.

Quando o assunto é variação linguística, o MEC costuma avaliar os livros didáticos seguindo alguns critérios, como:

$>$ não veicular preconceitos contra quaisquer variedades linguísticas;

$>$ apresentar textos representativos de diferentes variedades sociais, regionais e estilísticas; 
considerar as diferentes variedades linguísticas no âmbito da leitura, da produção textual e da oralidade;

$>$ estimular a reflexão sobre as formas linguísticas, relacionando-as com o uso e com os sentidos que elas mobilizam etc.

A variação linguística é uma realidade que, embora estudada pela sociolinguística, provoca reações sociais muito negativas. Alguns professores ver como desafio lidar com a incerteza e a heterogeneidade da língua, pois a sua identidade do professor de português como aquele que sabe "o português correto", pode ser questionada. Os próprios alunos em sala de aula têm um comportamento bastante preconceituoso quando o assunto é a Língua Portuguesa. Eles são categóricos em dizer que o outro fala errado e não sabe português, mas eles, enquanto usuários da língua, nunca falam "errado". Mesmo após uma aula onde o assunto tratado é a variedade linguística onde é apresentada todas as variedades como importantes para a comunicação, não havendo superioridade entre elas, os alunos não conseguem compreender, internalizar o que é ensinado em sala de aula para ser menos preconceituosos.

Uma atitude preconceituosa do senso comum que tem escassa percepção da língua como um fenômeno heterogêneo é aceitável, até pela falta dessa percepção, mas o preconceito vindo de pessoas que conhecem o quanto a língua pode variar, mudar e que para sobreviver, é fundamental que ocorra essas mudanças, é inaceitável, pois parte de uma boa educação de qualidade tem a ver com o ensino de língua, um ensino que garanta o domínio das práticas socioculturais de leitura, escrita e fala nos espaços públicos. E esse domínio inclui o das variedades linguísticas.

\section{Referências}

BAGNO, M. A inevitável travessia: da prescrição gramatical à educação linguística. In: BAGNO, M., STUBBS, M. \& GAGNÉ, G. Língua Materna: letramento, variação \& ensino. São Paulo: Parábola, 2002. . A norma oculta: Língua \& Poder na Sociedade Brasileira. São Paulo: Parábola, 2003. Nada na língua é por acaso: por uma pedagogia da variação linguística. São Paulo: Parábola, 2007. Sete erros aos quatro ventos: a variação linguística no ensino de português. São Paulo: Parábola, 2013.

BECHARA, E. Ensino da Gramática. Opressão? Liberdade? 6ª ed. São Paulo: Editora Ática, 1991 BORTONI-RICARDO. S. M. Educação em língua materna: a sociolinguística na sala de aula. São Paulo: Parábola, 2004. . Nós cheguemos na escola, e agora? São Paulo: Parábola, 2005. 
O professor-pesquisador: introdução à pesquisa qualitativa. São Paulo, Parábola, 2008.

BRASIL. Parâmetros curriculares nacionais: língua portuguesa. Brasília: MEC/Secretaria de Educação Fundamental, 1997.

Parâmetros curriculares nacionais: língua portuguesa. Brasília: MEC/SEF, 1998.

CASTILHO, Ataliba Teixeira de. Variação dialetal e ensino institucionalizado da língua portuguesa. In: BAGNO, Marcos. Linguística da norma. São Paulo, Edições Loyola, 2002, p.27-35.

DELMANTO, D. CARVALHO, L. B. de. Jornadas.port - língua portuguesa. 2.ed. São Paulo: Saraiva, 2012. (Coleção)

FARACO, C. A. Norma culta brasileira: desatando alguns nós. São Paulo: Parábola, 2008.

; ZILLES, A. M. Para conhecer norma linguística. São Paulo: Contexto, 2017.

FIGUEIREDO, Laura de; BALTHASAR, Marisa; GOULART, Shirley. Singular e Plural: Leitura, produção e estudos de linguagem. $2^{\text {a }}$ ed. São Paulo: Moderna, 2015.

HORA, Dermeval da. Variação dialetal e atitude. In: ; NEGRÃO, Esmeralda Vailati (Orgs.). Estudos da Linguagem: casamento entre temas e perspectivas. João Pessoa: Ideia/Editora Universitária, 2011.

LABOV, William. Padrões Sociolinguísticos. Trad. M. Bagno, M. M. P. Scherre e C. R. Cardoso. São Paulo: Parábola, 2008 [1972].

LAJOLO, Marisa. Do mundo da leitura para a leitura do mundo. 6. ed. São Paulo: Ática, 1996. LIBÂNEO, José Carlos. Didática: velhos e novos tempos. Edição do Autor, maio de 2002.

MARTINS, M. Antônio, VIEIRA, S. Rodrigues, TAVARES, M. Alice (orgs.). Ensino de Português e Sociolinguística. São Paulo: Contexto, 2014.

MILROY, James. Ideologias linguísticas e as consequências da padronização. In: LAGARES, Xoán Carlos; BAGNO, Marcos (orgs.). Políticas da norma e conflitos linguísticos. Trad. Marcos Bagno. São Paulo: Parábola, 2011. 